\title{
La lectura en la sociedad contemporánea
}

\author{
ELSA M. RAMÍREZ LEYVA \\ Centro Universitario de Investigaciones Bibliotecológicas \\ de la UNAM, 04510, México, D.F., Tel: (525)623-03-29 \\ E-mail: eramirez@ servidor.unam.mx
}

\section{RESUMEN}

...la namativa de los miltimedios induye representaciones tan espeáficas, que cada vez es menos lo que se puedeimagnar. La palabra escita, por \& contraico, describe imágenes y evoca mtáforas ayo sentido profundb surge a partir de la imaginacón y delas experienias personales di letar. Nicholas Negroponte

La lectura en la sociedad contemporánea se ha tomado más compleja por estar inmersa en una cultura mediática, pero además la industria editorial ha multiplicado y diversificado sus productos editoriales para el consumo. A esto ahora se suman también los medios digitales con una oferta informativa y de actividades a través de un solo aparato, la computadora, y un medio; la Internet. Todo ello forma parte de la naciente sociedad de la información que tiendea depender de la tecnología de la información, así como de las capacidades y habilidades de sus ciudadanos para generar conocimiento y desarrollos a partir de su transformación e información, tecnología y cultura. A partir de este contexto se aborda en el presente artículo la biblioteca, en particular la pública, como la otra opción para la lectura en un mundo que tiende a hacer de ella una actividad utilitaria y efímera y reducida al mero entretenimiento trivial.

Palabras clave: Lectura y cultura, Lectura y biblioteca pública, Lectura y sociedad de la información, Lectura y medios masivos de comunicación.

\section{READING IN CONTEMPORARY SOCIETY \\ ELSA M. RAMÍREZ-LEYVA}

\section{ABST RACT}

Reading in contemporary society has turned more complex as a result of its insertion in a media society. Also the publishing industry has multiplied and diversified the editorial products available on the market. Digital media offering information and activities using just one apparatus, the computer and one medium, the Internet, have also been added. All this forms part of the nascent information society with its tendency to depend upon information technology, as well as the capabilities and skills of its citizens to generate knowledge and developments viaits transformation and information, technology and culture. Parting from this context in the present article the library is presented, in
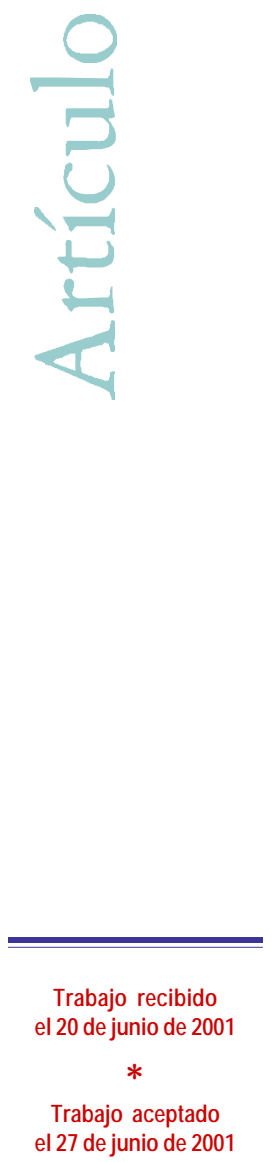
particular the public library, as the other option for reading in a world that tends to make of this a utilitarian and ephemeral activity reduced to mere trivial entertainment

Key words: Culture and Reading, Reading and Public Library, Reading and Information Society, Reading and Mass Media.

\section{INTRODUCCIÓN}

a lectura es un fenómeno cultural complejo en el que intervienen distintos factores: el nivel educativo, las condiciones socioeconómicas, la historia y la tradición lectora de cada sociedad, así como la producción, distribución y difusión de los materiales de lectura por medios públicos o privados. A nivel individual, en la lectura se involucran también la historia personal, el momento y las motivaciones del sujeto; el grupo social a que pertenece y el contexto que lo rodea.

Por lo tanto, en cada civilización se observan diferentes formas y medios de informar y de informarse, de escribir, de leer y de interactuar. Por eso la lectura es un indicador del nivel cultural de la sociedad y de los individuos.

El estudio de la lectura abre horizontes históricos y sociales que nos permiten conocer las mentalidades y las prácticas culturales características de épocas y grupos ancestrales. Sin embargo son pocos y sumamente complicados los estudios que se han realizado sobre los efectos que puede producir la lectura y sobre determinadas lecturas en épocas concretas y en estratos sociales específicos o generales. ${ }^{1}$ En cambio son más los análisis cuantitativos orientados al consumo cultural de esta actividad, cuya premisa parece basarse en el hecho de que leer mucho da como resultado saber más, ser más culto - valores que supuestamente pueden lograrse mediante la lectura de muchos libros.

Los datos que se han recabado sobre la cantidad de libros, periódicos, revistas, y otros tipos de impresos adquiridos y leídos, así como sobre la asistencia a las bibliotecas, más las variables edad, escolaridad, ocupación, género y nivel socio económico, se utilizan para elaborar la tipología de las prácticas de lectura y los lectores. Asimismo esta información cuantitativa ha servido para identificar el progreso de la sociedad en materia de cultura y educación.

No obstante, los estudios cuantitativos sobre la lectura por lo general excluyen el material calificado como ligero, efímero o frívolo; ${ }^{2}$ es decir los lectores de esta literatura son sumados a los no-lectores o simplemente no son tomados en cuenta.

1 Algunos trabajos realizados por Robert D arnton y Roger Chartier abordan más bien aspectos de carácter cualitativo respecto de las prácticas de la lectura.

2 Ya desde el siglo XVI, en Europa occidental las novelas de caballería se consideraban lecturas populares cuyo contenido era de dudosa calidad y hasta peligroso, al grado de que se prohibía su lectura. 
Cabría entonces preguntarse ¿qué es leer? Lo cual, dada su complejidad, resultaría difícil de contestar concretamente sin dar lugar a posibles contradicciones, particularmente cuanto se encuentra frente a la literatura de entretenimiento, historietas, comics u los textos digitales, debido a las consideraciones que señalan que era literatura no se puede considerar como lectura.

Ante este panorama resulta primordial que la biblioteca pública sea una alternativa para la lectura y la información, y aminore el riesgo de que la llamada sociedad de la información cree, paradójicamente, un estado de desinformación masiva. Por ello este artículo propone reorientar la biblioteca pública como una opción que incluso permita el desarrollo de guías electrónicas para la lectura (reading advisory) con el fin de que los usuarios cuenten con los elementos que les permitan seleccionar lecturas y fuentes informativas frente a la avalancha documental impresa y electrónica.

\section{LA SOCIEDAD CONTEMPORÁNEA}

Es común que a las sociedades se las denomine de acuerdo con el símbolo que representa su forma predominante de producción y de organización social; de esta suerte a la sociedad contemporánea se la ha empezado a denominar "de la información" o "del conocimiento". Si bien es cierto que la información forma parte del origen de la vida y siempre ha estado presente de manera implícita o explícita en el desarrollo de la humanidad, es sólo ahora cuando parece emerger y "develarse" como recurso estratégico para el desarrollo económico, cultural y tecnológico. No sorprende que sean los países más avanzados los que han apoyado más la investigación como proceso generador de los nuevos conocimientos y desarrollos tecnológicos. D e hecho, el ser humano de todas las épocas ha ideado diversas formas para comunicar y registrar la información, y éstas han alcanzado su máximo desarrollo con la escritura y el formato colex. D espués la imprenta se encargó de darle al libro una difusión sin precedentes. Sin embargo para llegar a los medios digitales actuales tanto el pensamiento como los materiales y las herramientas creados por el hombre moderno debieron pasar por varias etapas de evolución para generar un sistema social de comunicación escrita en el que participan diferentes medios, formas y procesos que tienen como base la información y la tecnología.

Pese a que los teóricos sociales siguen analizando y enfrascándose en discusiones sobre la pertinencia de la denominación y las características de la sociedad de la información, y sobre las virtudes y peligros del nuevo modelo social, éste se ha constituido ya como el paradigma del Siglo XXI. Incluso ya es posible identificar las naciones que más se acercan a él (Estados Unidos, G ran Bretaña, la Comunidad Europea, Japón), en tanto que otros países se esfuerzan por desarrollar un plan oficial para acercarse al nuevo modelo: en América Latina se encuentran Brasil y Chile de manera independiente pero también en el grupo del MERCOSUR. Incluso aquellos países cuyos objetivos y acciones no tienen expresamente un proyecto de 
sociedad de la información empiezan a seguir las nuevas tendencias. Sin embargo estos últimos cimentan peligrosamente su modernización en la instalación de equipos de cómputo y telefonía - sin tomar en cuenta que éstos sólo son medios para llegar a los contenidos- , 0 en conectarse a inteme para obtener información diversa, sin darse cuenta de que corren el riesgo de que la información local sea la gran ausente.

Es interesante sin embargo encontrar, entre los proyectos relacionados con el desarrollo del nuevo modelo social, rubros destinados al fortalecimiento de programas de fomento a la lectura y a la biblioteca pública, aun cuando también los programas de las Bibliotecas Nacionales, se proponen salvaguardar y difundir el patrimonio documental.

Para definir la "sociedad de la información", según F. Webster, ${ }^{3}$ existen diferentes enfoques: el tecnológico, el económico, el ocupacional, el espacial y el cultural. El enfoque tecnológico considera que la revolución tecnológica, el avance en las telecomunicaciones y la coincidencia de ambas, vinieron a transformar los procesos de almacenamiento y transmisión de la información en una estructura hecha de redes y supercarreteras capaces de conectar a todo el mundo. Esta tecnología se constituye en la infraestructura de la nueva sociedad y deja entrever la idea de un determinismo tecnológico.

Respecto del enfoque económico, Fritz Machlup y Mark Porat, ${ }^{4}$ dividen a la sociedad de la información en dos grandes sectores: quienes la crean y quienes la comunican, y ambos convergen en otros cinco, a saber:

1. El educativo (instituciones educativas, bibliotecas).

2. Los medios masivos de comunicación (TV, radio, periódicos).

3. El equipamiento (computadoras, programas, cables y demás aparatos).

4. Los servicios de información y las telecomunicaciones.

5. Las actividades de información (actividades científicas).

El tercer enfoque, el ocupacional, se centra en los cambios que han experimentado las actividades productiva y de servicios de información, así como en el incremento del número de personas que laboran tanto en la creación, proceso y manejo de la información, como en la producción y venta de productos informativos. Se incluye aquí a profesores, investigadores, bibliotecólogos, periodistas y computólogos, quienes entre otras actividades se dedican a reunir y diseminar información, procesar y generar productos, e incluso a operar la tecnología.

El enfoque espacial pone énfasis en la interrelación, es decir, en la formación de redes (lo cual incide en las dimensiones de tiempo y espacio), en las que la informa-

3 Frank Webster. Theories of theinfomation socity. Londres y Nueva Y ork: Routledge, 1999, p. 6.

4 Fritz Machlup. The study of infomation, 1983 y Mark Porat. The infomation economy: sarces and mothods for masuing the primary information setor [1977-12(2)], citados por Frank Webster, quat, pp. 10-13. 
ción y la tecnología ocupan un lugar central y estratégico, ya que la organización de las demás actividades depende de la información, y que la tecnología es la infraestructura que permite el proceso y distribución o circulación de ésta a través de la industria de la información. Esto produce el consecuente crecimiento de los servicios y nuevos medios de comunicación, y una multiplicación de bases de datos de muy diversa índole que hacen más poderosas las redes, todo lo cual favorece la integración de las economías regionales, nacionales y globalizadas.

Finalmente, el enfoque cultural considera que la capacidad de penetración que poseen en el tratamiento social la tecnología y los medios masivos de comunicación -y sus contenidos- , permite transmitir y obtener distintas expresiones culturales, y proporciona el acceso a museos, bibliotecas, imágenes, música, diarios, revistas, e información sobre los espectáculos, más la posibilidad de personalizarlos de acuerdo con el gusto de los usuarios (desde luego con una oferta limitada, es decir, preseleccionada y manipulada). En este contexto, el uso de la inteme es cada vez mayor para interconectar a las personas entre sí y a éstas con una vasta oferta de información, servicios y productos relativos a actividades educativas, científicas, informativas, de entretenimiento y comerciales, y a la vez ha aumentado el poder de integración de otros medios: radio, TV, teléfono y cine. De ello han surgido nuevas formas de producir, comunicar y usar el conocimiento; y nuevas formas de relaciones humanas no limitadas a un ámbito local sino extendibles a todo el mundo, siempre y cuando exita interconexión.

Con base en lo anterior, podríamos resumir que la sociedad de la información es una sociedad altamente interconectada e interdependiente, que tiende a incluir todas las actividades y relaciones humanas mediante una estructura tecnológica globalizadora en red, a través de la cual fluye la comunicación y la información y se construyen -y de ella dependen- las nuevas formas de expresión cultural, las actividades productivas, económicas, educativas y de entretenimiento, y las relaciones humanas, todo mediado por la tecnología y la información.

El grupo de investigadores del CUIB que trabajamos en el proyecto HadalaSocielad dela Infomaión en México hemos propuesto otra definición, una: "Nueva forma de organización y espacio social de carácter complejo, altamente dinámico, diverso, abierto, globalizado y tecnologizado, integrado por un conjunto de comunidades sociales condicionadas por factores de tipo económico, tecnológico, políticoideológico, cultural, educacional e informacional, en donde la información se convierte en un recurso para el desarrollo social y sustento del conjunto de las relaciones sociales."

D esde la perspectiva anterior la sociedad global de la información serán los países o los sectores más desarrollados de la sociedad, los que podrán obtener mejores y

5 Hacia la Sociedad dela Información en Méxica Coordinado por Roberto G arduño, Ramiro Lafuente y Elsa Ramírez. http:/ / cuib.unam.mx/ investigación/ soc_inf/ soc_inf2.htm 
mayores oportunidades para sus ciudadanos. Pero en aquellos países que se encuentran en situación menos ventajosa deberán ser los go biernos los que tendrán que facilitar el acceso a los recursos y servicios que ofrece la tecnología de la información (educación, servicios, etcétera). Todo esto encaminado a generar beneficios y avances en la medida en que recae la importancia que tienen las capacidades para usar, explotar y desarrollar tanto la propia tecnología como lo que se puede obtener con ella.

Pero esta sociedad de la información está propiciando lo que se ha denominado "digital divide"; es decir, una nueva división entre países ricos y pobres, o entre las personas que tienen acceso a las redes electrónicas y las que viven fuera del mundo cibernético, lo cual ahonda la fractura social existente y orilla a los países menos desarrollados a ser más dependientes en el sentido de tener que consumir lo que otros producen en materia de información y tecnología. Por lo tanto debe ser motivo de atención para nuestras sociedades que, apareado con el consumo tecnológico, se importe el contenido informativo, con el consiguiente riesgo no sólo de propiciar el incremento de las masas proletarias sino, lo más dramático: de perder nuestros referentes culturales. Esto no sucederá siempre y cuando la sociedad civil y sus instituciones tomen el control de los contenidos y de sus usos, porque de lo contrario estarán a expensas de los poderosos consorcios que atizan y están logrando una transnacionalización económica de la cultura reduciéndola a mercancías que aportan jugosos dividendos y convierten a los individuos en meros espectadores y consumidores.

\section{LA CULTURA (SER Y SABER) EN LA SOCIEDAD CONTEMPORÁNEA}

Si bien la televisión puede considerarse como un progreso tecnológico sin precedentes, dada su capacidad de expansión y penetración en el sistema social de comunicación, el hecho de haber sido acaparada por el sector empresarial ha causado que sus contenidos se orienten fundamentalmente a satisfacer los intereses económicos y de poder de este sector, compitiendo incluso actualmente con el Estado.

El hecho de que las empresas televisoras hayan adquirido o tengan inversiones en la radio, los espectáculos, los deportes y en algunas actividades culturales y de servicios, les ha permitido aumentar aún más su influencia en la sociedad. Incluso se dice que de continuarse con la integración de todos los medios (televisión, radio, cine, prensa, incluidos libros y revistas, telefonía e Inteme), éstos quedarán en manos de unas cuantas empresas que, convertidas en poderosos consorcios, serán los dueños 0 socios de empresas no solamente privadas sino también públicas, otrora nacionales, de comunicación, información y culturales.

Al invadir los espacios privados de los hogares, la denominada cultura mediática, ha logrado, en 50 años, imponerse y formar públicos masivos valiéndose de una gran variedad de alternativas -la mayoría de ellas insulsas- de entretenimiento e 
información para divertir y entretener en la seguridad del hogar, sin que los usuarios tengan que hacer ningún esfuerzo mental, y a un costo bajo.

Además los medios masivos de comunicación y en particular la televisión no sólo han logrado atraer a los públicos de otros sectores (cine, teatro, salas de conciertos, estadios) sino que les han restado tiempo para realizar otras actividades como la lectura y la convivencia familiar, y a todos nos ha metido en el fast thinking pues en los medios cada minuto, cada palabra, tiene un costo y por lo mismo se usa el mínimo de imágenes y frases, el resultado de lo cual es que de la enorme cantidad de información que se lanza en espacios reducidos de tiempo o tinta, sólo se pueda recordar un mínimo. Así, en una suerte de alquimia, las tradiciones, las actividades sociales, políticas, religiosas, personales y hasta las familiares, son transformados en espectáculos banalizados por medio de un esquema de entretenimiento suficientemente impactante.

La cultura mediática - como ya se señaló- incluye los medios escritos, algunos de los cuales ya están en manos de emporios de televisión, radio y prensa, en tanto que otras empresas comerciales han adquirido casas editoras y librerías, algunas de ellas de gran tradición "Estos nuevos propietarios exigen rentabilidad de los productos editoriales, al igual que sucede con los periódicos, la televisión, el radio, el cine. Modifican la naturaleza de los contenidos de los libros y para ello se basan en el sistema 'best sellers' de las películas de éxito por ejemplo, la D isney Corporation publica libros mediante su casa editora Hyperion. Las empresas televisoras también orientan sus ediciones hacia temas que se relacionan con sus programas sean de entretenimiento o de 'superación personal'. Estas empresas además tienen los canales de distribución que forman redes locales regionales e internacionales, y traducen sus productos en los distintos idiomas de sus mercados." 6 D e este modo, al adueñarse de la producción, distribución y venta de libros, revistas y diarios, al igual que de programas de TV y de radio, esas empresas adquieren un dominio absoluto sobre los contenidos de los mensajes, que llenan principalmente de publicidad y entretenimiento; fabrican así arquetipos, deseos, y necesidades, forman opinión, establecen un lenguaje y entretienen de manera fácil, por lo que el lector o el televidente no necesitan hacer el menor esfuerzo mental. Como señala Sartori, ${ }^{7}$ se produce el fenómeno de informarse viendb, situación que desde luego no es nueva; la diferencia radica en el aparato que transmite contenidos seleccionados previamente por otros, los cuales, como ya se mencionó, no son innocuos, pues conllevan la intención de quien los produce y/ o transmite.

El contexto social actual, con los adelantos que ofrecen la tecnología de la información y las telecomunicaciones - aparentemente en transición a la sociedad de la información-, se distingue por la emergente tecnología digital que articula los medios

6 André Schiffin. La edicoón sin editores, Barcelona : D estino, 2000, p. 79.

7 Giovanni, Sartori. Hom vidans La soiedad tdedirigda, México: Taurus, 2000, p. 35. 
masivos (el televisor, la prensa, la radio, la telefonía) y da lugar a un poderoso hipermedio en el que todos éstos pueden interactuar y, a través de un solo aparato, acceder a cada uno de ellos; es decir, a través de la pantalla de la computadora se pueden integrar distintos elementos, reorganizarlos, vincularlos con otros recursos, interactuar con ellos y luego transferirlos.

$\mathrm{Al}$ surgir las computadoras personales en plena cultura mediática, la sociedad -ya habituada a la pantalla- no tuvo dificultad para iniciarse en el manejo del Inteme, y empezar a adentrarse en las redes los medios digitales, la tecnología de la información, las telecomunicaciones y formas textuales y audiovisuales interactuantes entre sí que manipulan al individuo. Con esta tecnología se han creado nuevos objetos que permiten conocer una forma de la realidad. Incluso se han empezado a substituir los espacios en donde se solían establecer las relaciones humanas: el café, el bar, el salón de clases, la oficina, el parque, la plaza pública, la biblioteca y hasta los lugares emblemáticos. A hora se han iniciado estos encuentros humanos en un mismo sitio (Inteme), y a la vez se han generado nuevas prácticas informativas y de lectura cuyas características distintivas son los cambios en las dimensiones de tiempo y espacio, que permiten la combinación de texto, imagen, sonido y todos los elementos digitales desarrollados hasta ahora, así como la interconexión, la interactividad y la intercomunicación con distintos sitios, todo lo cual según ha deducido Jeremy Rifkin, favorecen el acceder más que el poseer “...de manera creciente, de la misma manera que en otras áreas de la emergente economía-red, las relaciones entre compradores y vendedores se van reemplazando lentamente por la de proveedores-usuarios o servidores-clientes, señalando el tránsito de la era de la propiedad hacia el surgimiento de la era del acceso." ${ }^{8}$

Hoy para poder "ser" es obligado estar conectado a ése que parece un mundo paralelo, denominado "ciberespacio" o "mundo virtual", lo cual implica contar con una "dirección" o página electrónica, e informar e informarse a través del nuevo medio. $Y$ a las generaciones de niños y jóvenes habitantes del ciberespacio se las identifica como la "generacóncom", porque es en el supermedio inteme donde se divierten, se comunican, se informan, aprenden, compran, venden y establecen relaciones humanas. Se trata de un mundo donde ha empezado a surgir la cibercultura o la cultura digital y en el que, aunque parece prevalecer la participación de la sociedad civil, paulatinamente el sector empresarial ha empezado a acaparar sus contenidos; de la misma manera que ya lo hizo antes con la TV, la radio, la prensa y el mundo editorial.

En síntesis, la cultura contemporánea ha dado lugar a una sociedad mediática, masificada, individualista, en busca de identificación y domesticada por los multimedios masivos "que están dejando de ser medios de comunicación de ma- 
sas para convertirse en medios de producción masiva de mensajes, imágenes y sonidos," ${ }^{9}$ y también está mediatizada por el consumismo, el amarillismo, el mensaje rápido y fácil, y los contenidos frívolos disfrazados de espectáculo. E sta cultura, dice Sartori, ${ }^{10}$ "...ha dado lugar a una sociedad reblandecida por la multimedialidad, ha producido un proletariado intelectual y se ha multiplicado; ahora los medios son la autoridad del saber popular y están en los lugares que antes ocupaban los sabios."

Pero la sociedad de la información, con todo y la poderosa tecnología y las telecomunicaciones que la sustentan, con todo el equipamiento que la caracteriza (televisión, radio, teléfono e internet, que cada vez se extienden a sectores más amplios de la sociedad); con el enorme flujo de información accesible en diferentes medios, puede, paradójicamente provocar el fenómeno de la desinformación o el vacío informativo al dificultar la selección de la información pertinente, particularmente entre quienes no tienen la capacidad de discriminar la calidad de la oferta informativa, o bien por existir limitantes en cuanto a las habilidades requeridas para moverse en el ciberespacio que exige la sociedad de la información.

\section{LA LECTURA EN LA SOCIEDAD ACTUAL}

Los medios masivos de comunicación, como ya se señaló, han desarrollado una cultura que se caracteriza por la inmediatez, es decir, por querer informarse en el menor tiempo y con el menor esfuerzo físico y mental posibles; una cultura de consumo más bien orientada hacia el acceso, 0 el acceder.

Por su parte, los sistemas educativos se limitan a cumplir cuantitativamente con los tiempos establecidos y con las metas de enseñanza a que obliga un programa. Se convive a la par con una cultura mediática, que ha devorado -incluso en los países desarrollados- los procesos mentales y educativos, lo cual se aprecia con mayor intensidad en los países de economías vulnerables que no han logrado alcanzar ni siquiera los índices de financiamiento (8\% de PIB) recomendados por la UNESCO para la educación. De esta suerte, la formación en las instituciones educativas que cuentan con apoyos limitados (de bibliotecas, laboratorios, etcétera), se ha concretado - sobre todo en los países en proceso de desarrollo- en un proceso de aprendizaje de la lectura que decodifica letras pero no lee contenidos, lo cual produce que la lectura sea fundamentalmente utilitaria, puesto que se usa para resolver necesidades específicas de estudio o de información, pero una vez satisfecha esta necesidad la lectura es relegada hasta que surge nuevamente la necesidad de acudir a ella.

9 Francisco Aguadero Fernández. La sociedad dela infomacón: vivir en e sigo XX, Madrid: Acento Editorial, 1997, p. 17.

10 Santori, qp at, p. 145. 
En cuanto a la lectura de esparcimiento ésta tiene dos vertientes: la de la lectura que se practica por convicción como un medio para propiciar placer, enriquecer la mente, ampliar el capital lingüístico y cultural; es decir, una lectura que permite apropiarse de las ideas, de los hechos, de los lugares, una lectura que implica un estado de fusión entre el texto y el lector, y de la que surgen la imaginación y la emoción en el momento en que el texto cobra vida. La otra vertiente es la de la lectura que se hace como un pasatiempo efímero, aquí las habilidades del lector, su experiencia con la lectura y su motivación se limitan a enterarse, mas no a obtener conocimiento.

Si consideramos que la lectura es la base del proceso educativo que Paulo Freire ${ }^{11}$ define "como un acto de conocimiento y como un acto político, que tiende a la transformación del hombre en cuanto a clase social y de su mundo," entonces la lectura y los textos son lo que permite llevar a cabo ese acto, siempre y cuando el lector desarrolle su capacidad para comprender, seleccionar y reflexionar aquellos textos cuyos contenidos le ofrecen los conocimientos indispensables para producir en él una transformación positiva, mediante el proceso educativo señalado por Freire. Pero frente a este ideal educativo se reproduce - en no pocas institucionesun aprendizaje basado en lo enciclopédico y lo memorístico.

Contrariamente, los sectores mercantiles y mediáticos han utilizado la lectura en su beneficio, la han convertido en un instrumento para reproducir y fortalecer sus intereses, es decir, el consumo de sus productos e ideas. Y con el fin de controlar su mercado y de ser más directos y contundentes, sectorizan a la sociedad, que a la vez se globaliza, de tal manera que los públicos se vayan inclinando por valores, arquetipos y hábitos de consumo similares o iguales a los de otros países: grupos musicales, ropa de determinadas marcas, comida, bebidas, deportes, aspecto físico, lecturas, sitios electrónicos, programas de televisión, películas, etcétera, lo que a su vez va determinando una forma de pensar, o de "ser".

Es de suponer que la lectura produce diferentes efectos en cada sujeto de acuerdo con su circunstancia, desde luego. Por lo tanto, leer es algo que puede considerarse como una premisa respaldada por una convicción, fortalecida por su vinculación con el libro, que simboliza el conocimiento (que pese a todo parece persistir). Así, libro y lectura forman parte del proceso cognitivo. En este sentido dice Jesse Shera que "los efectos de la lectura dependen de lo que haya para leer, y lo que está disponible para ser leído está determinado por factores socioeconómicos, culturales y los de cada individuo y del grupo al que pertenece." 12

Ahora los medios de comunicación y los digitales invierten sumas considerables de dinero en productos editoriales impresos y electrónicos, y la lectura se promueve a través de la derrama de miles de ejemplares cuyos contenidos no están muy alejados de aquellos que ofrece la televisión. Así, la lectura que debería suscita un "atreverse

11 Paulo Freire. La impatania delerry d proceso deliberacón México: Siglo XXI Editores, 1985, p. [7].

12 Jesse Shera. Los fundamentos de la educacón biblidtedoógica, México: UNAM-CUIB, 1990, p. 34. 
a pensar" o a asumir el derecho de pensar (lo cual - dicho sea de paso- representa un riesgo para muchos), o a pensar diferente, se elimina. Lo que se enseña es a leer para no comprender, o a hacer lecturas que no proporcionan conocimiento, que no despierten la imaginación; no se enseña a pensar, lo que interesa es únicamente reproducir los modelos impuestos por los medios masivos de comunicación.

Esto explica las preferencias de un amplio número de lectores que abreva en la abundante producción de revistas de entretenimiento, de historietas, y de comics en las que predomina la imagen y el texto se constriñe en frases breves y un limitado lenguaje coloquial, lo que engendra una lectura que no enriquece el capital lingüístico ni ejercita la capacidad de comprender y reflexionar sobre lo leído. La lectura que se ofrece en estas revistas se reduce a un mero acto de repetición, un pobre manejo del lenguaje, y un vocabulario reducido igual o semejante al que ha sido imbuido en buena medida por los programas de televisión y por los artistas del momento, quienes ahora resultan ser el prototipo a seguir.

Es importante tener en cuenta que la lectura, además de estar determinada por el contenido, también incide en la distribución de los libros, revistas y periódicos. Al respecto Shera ${ }^{13}$ apunta que el sistema de distribución, exhibe tanto un efecto negativo como uno positivo: es negativo cuando no satisface el deseo del lector; es positivo cuando reúne a lectores y publicaciones compatibles. En este sentido, el margen de libertad de selección de lecturas dentro del mercado editorial y de distribución es proporcional a los factores individuales y sociales que predisponen al lector a determinadas lecturas.

Sin duda la venta de libros y revistas de entretenimiento es un negocio tan lucrativo que empresas en absoluto relacionadas con la edición, y dueñas ahora de casas editoras las transforman en fábricas de títulos lucrativos, con la única intención de obtener mayores ganancias. Estos empresarios editan libros y revistas que logran insertar en los mercados regionales o internacionales, o compran las franquicias para traducir títulos que producen editores cada vez más trasnacionalizados. ${ }^{14}$

A la par, el fenómeno, Inteme, ocupa de manera acelerada espacios informativos, de lectura y de educación. Los datos que se tienen al respecto permiten corroborar cómo Inteme ha ido acaparando estas actividades, y observar las expectativas que tienen los usuarios en este supermedio del mundo cibernético. Para darnos una idea de la rapidez con que se ha extendido su uso, tenemos que en diciembre de 1995 sólo 16.0 millones de personas, o sea, .39\% de la población mundial utilizaba Inteme; y para en noviembre del 2000, esas cifras se incrementaron

13 Shera, qu at, p. 34-35.

14 Veáse la obra de Schiffrin. La eedián sin editores donde el autor relata la forma en que el sector editorial es transformado en una empresa de producción de textos fácil y rapidamente comercializables. Incluso casas editoras y librerías de prestigio han sucumbido ante la economía de mercado. 
a 407.1 millones de personas conectadas a la red, (6.71\%); es decir, un crecimiento de más de $1000 \%$ en cinco años. A continuación se proporcionan gráficas significativas obtenidas por la firma NUA Analysisque nos ilustran al respecto.

\section{Principales usos del Intemet durante 1998}

Uno de los servicios más utilizados en Internet es el de información. Vemosaquí su uso en relación con actividades educativas, laborales y de entretenimiento.

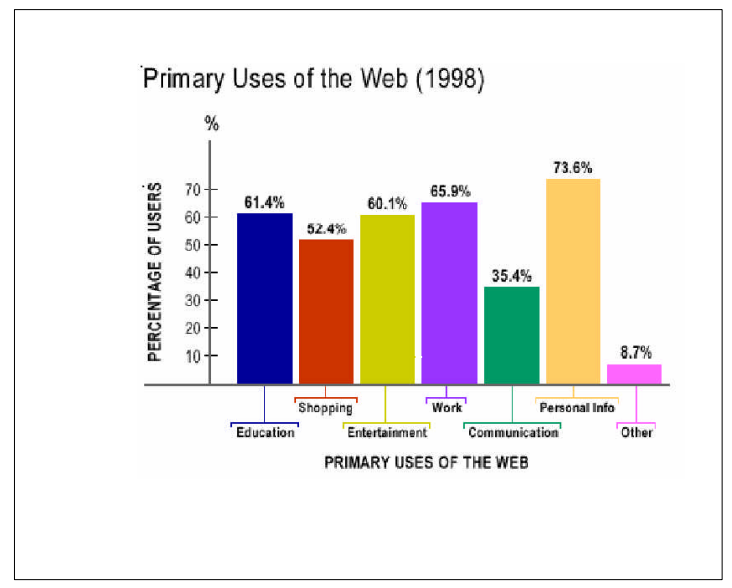

\section{El internet desplaza a la TV y al uso del teléfono}

Internet empieza a sustituir el uso de ciertos medios como la TV y el teléfono, pero también a la lectura de revistas y diarios

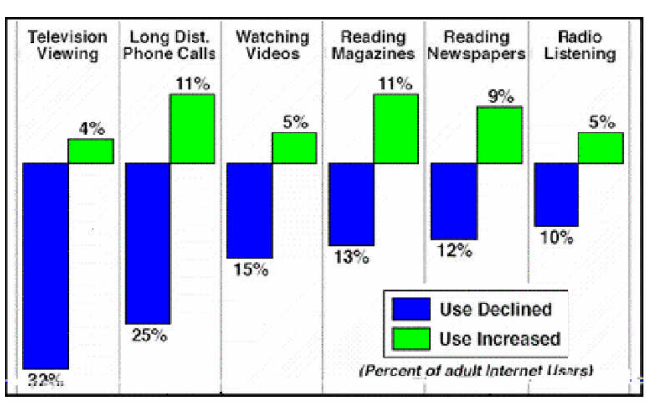




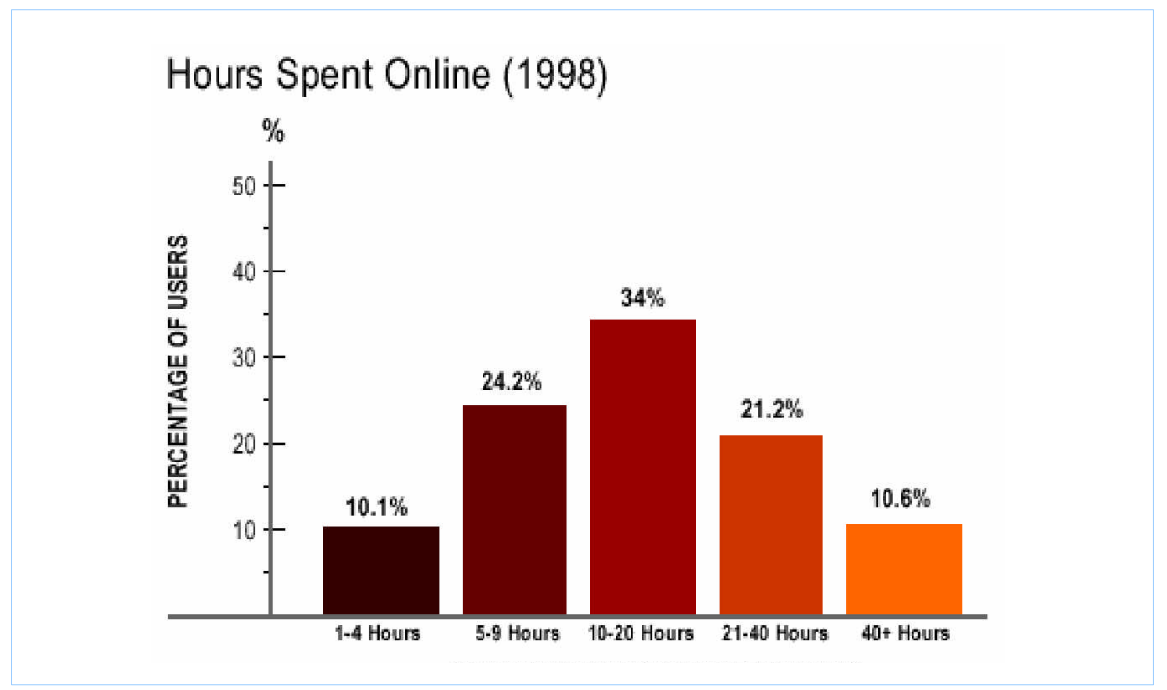

Fuente: Gvu Surveys. Nua Graphics

Una de las virtudes que se le adjudican a la sociedad de la información es que la globalización facilitará la disponibilidad de la información que se produce en el mundo entero. Pero esta virtud es opacada por la comercialización y el lucro de los denominados productos informativos y de lectura introducidos en la red por las grandes empresas, los cuales, desgraciadamente, en un tiempo no muy lejano, podrían ser la única alternativa de información. Este fenómeno ya se ha iniciado, como podemos ver con la publicación de revistas académicas en versión electrónica, la repercusión de lo cual ha alcanzado el trabajo de los científicos, quienes muestran una clara preferencia por ellas y consideran como una de sus ventajas la posibilidad de trabajar desde cualquier lugar - incluso de manera colectiva- con el 0 los autores de los artículos. ${ }^{15}$ En respuesta a esta comercialización, las casas editoras han optado por suprimir sus versiones impresas y las bibliotecas por su parte han empezado a cancelar suscripciones a revistas impresas, al tener acceso a las electrónicas.

La lectura en la pantalla bajo los principios de rapidez y facilidad, ayudada con la proliferación de imágenes e íconos, obliga a los textos a cumplir con las condicio-

15 Revisar los artículos de Elaine D avis Smith. A comparison of the effects of a new technology on searching habits in industrial and academic institutions, publicado en el Joumal of Infomation Saience, no. 19, 1993, p. 57-66. Y el de Stephanie Publicker y Kristin Stokfosa. Reaching the researcher: how the National Institute of Health Library select and provides journals via World Wide Web, publicado en Seial Review v. 25, no. 3, 1999, p. 13-23. 
nes de brevedad y simplificación (como el lenguaje que se usa en los medios de comunicación, los comicso las historietas). Así, en la sociedad de la información la lectura corre el riesgo de quedar circunscrita a un ciclo determinado por los cánones que establezcan las tecnologías de la información y la comunicación, y sujeta a la capacidad de los lectores, para poder desprenderse de las preferencias que le han sido inculcadas por las empresas, las cuales se han apropiado de las mentes, las almas y los cuerpos de los individuos, sin importar si éstos pertenecen a países ricos o pobres.

No puede negarse la gran capacidad de Inteme para difundir la información, lo que no podría lograrse por otros medios limitados o condicionados por algún tipo de censura o los elevados costos de impresión. A demás, dada su gran capacidad, Inteme puede constituirse en un medio democrático ideal al que todos tengan acceso y del que tomen lainformación que consideren conveniente, pero su uso sería más ventajoso si se convirtiera en una eficiente fuente de información, lectura y comunicación y si las instituciones educativas proporcionarán capacitación en el manejo de las herramientas y formación para discriminar y aprovechar esa información.

Pero por otro lado resultaría contradictorio que la sociedad de la información, en lugar de producir conocimiento optara por la repetición más que por la innovación - camino a veces fácil- pero acaso la excesiva mercantilización haga de la información más novedosa un recurso tan costoso que sólo unos cuantos podrían consultarla; información privilegiada aún para quienes se pudieran conectar a la red. Fenómeno éste que podría conducir al vacío informativo como ya se mencionó, dada la avalancha de la oferta informativa de dudosa calidad y confiabilidad que ya hoy circula en las redes digitales, en las cuales se tiene la sensación de poder acceder a mayor información de manera más sencilla y rápida que por medio de la $\mathrm{TV}$, o recurriendo al kiosco de la esquina (con sus mercancías editoriales) 0 incluso a la entrega a domicilio de periódicos, libros y revistas.

\section{LA BIBLIOTECA PÚBLICA: LA OTRA OPCIÓN}

La institución bibliotecaria pública tiene una larga tradición de servicio y desde su creación en el siglo X IX ha cumplido con la función de poner a disposición de todo aquel que lo solicite, información y materiales de lectura de manera gratuita, con lo cual responde al ideal del derecho a la educación que incluye el derecho a la lectura y a la información.

En el contexto de la sociedad mediática, la biblioteca pública - creada como complemento y alternativa del proceso educativo- constituye una oferta de lectura distinta a la de los mercados, que derraman miles de ejemplares de libros y revistas; para adquirirlos por compra. La biblioteca pública es la oferta gratuita de lecturas seleccionadas bajo criterios que toman en cuenta la calidad de los materiales y las características y necesidades de su comunidad. 
Los gobiernos de algunos países, como es el caso de Estados Unidos, Argentina, México, España, Inglaterra, Alemania y Francia, entre otros, preocupados por contrarrestar el empobrecimiento de las capacidades lectoras y el incremento del consumo de libros de baja o nula calidad, y ante su inminente ingreso a la sociedad de la información, han decidido aplicar programas de fomento a la lectura tanto en el sistema escolarizado como entre la población en general. Incluso en algunos proyectos de soiecladdelainformacónse observa que se le da una particular atención al renglón de la biblioteca pública, como una de las instituciones capaces de disminuir las desigualdades que puede producir tanto el mundo digital como el impreso. La biblioteca pública se ha sostenido y desarrollado, desde su creación, con el presupuesto que le asigna el gobierno federal. En la historia reciente, sin embargo, al igual que otras instituciones de la misma condición, se ha visto afectada por las nuevas políticas gubernamentales que tienden a reducir los presupuestos destinados a los servicios públicos. Hoy, la esencia de la biblioteca pública, como señala Habermas ${ }^{16}$ y también alude Schiffrin, ${ }^{17}$ se encuentra ante una nueva concepción de servicio y acceso a la información: los servicios de préstamo interbibliotecario y el préstamo de materiales que no sean libros, son considerados como mercancías sujetas a las leyes de mercado en busca su rentabilidad.

La idea de asociar lo público con la gratuidad ha empezado a cambiar al grado de que se ha llegado a afirmar que las instituciones públicas (y gratuitas) se extinguirán si no adoptan una actitud empresarial. Pero una sociedad que no cuente con una biblioteca pública institucional (fundacional de la esfera pública) que ofrezca publicaciones y fuentes de información, empobrecerá enormemente el ambiente informativo de los ciudadanos, y aunque se repita que en Iinternet se puede acceder a casi toda la información, ésta no está libre de costos. ${ }^{18}$ Es un hecho que la sociedad de la información también necesita de las bibliotecas.

En algunos países europeos así como en los Estados Unidos y Canadá, las bibliotecas públicas han utilizado los avances tecnológicos para acercar a los usuarios a los servicios y las opciones informativas, a la vez que han hecho llegar éstos a sectores de la sociedad que no han tenido una relación importante con la biblioteca pública.

Incluir la biblioteca pública en el proyecto de sociedad de la información contribuirá a reducir el problema del "digital divide”, porque permitirá a los usuarios acceder no sólo a los materiales impresos y audiovisuales sino también a los digitales, pero no hay que caer en la ligereza de pensar que con sólo conectar las bibliotecas

16 Crr. Webster F. Op at, p. 111-116.

17 Schiffrin, A. Op at, p. 107.

18 No es casual que en la literatura bibliotecológica encontremos que el concepto de lector o usuario se haya transformado en el de cliente. Sin duda el lenguaje tiene un enorme poder y capacidad para introducir ideas, de las que luego se pasa a las conductas de manera subrepticia. 
a Internet se logra pasar a la modernidad. Y a los países desarrollados han invertido recursos para desarrollar sus bibliotecas públicas y sus actividades de fomento a la lectura, con esta integración de los avances cibernéticos aseguran la participación de su sociedad de manera significativa.

En conclusión, la biblioteca pública puede ser revalorada como "elemento clave para la realización local de la sociedad de la información"; es decir, un buen uso de la tecnología de la información puede fortalecer las funciones sustantivas de la biblioteca pública en el nuevo contexto social, en la medida en que: ${ }^{19}$

* facilite el acceso a los documentos y la información en cualquier tipo de soporte,

* abra espacios de acceso a la información de las áreas oficiales de gobierno dirigidas a la sociedad,

* proporcione espacios y equipamiento en el local de la biblioteca tanto para la lectura de material impreso como para acceder a la información,

* suministre servicios remotos para facilitar la consulta y el acceso a las fuentes informativas,

* diseñe servicios y fuentes informativas cuya consulta resulte sencilla y clara,

* organice, para su consulta, los sitios que desarrolla la sociedad civil (por ejemplo las guías de lectura (reading advisory) o las redes sociales (community networks),

* se inserte en los procesos laborales y educativos a distancia y tradicionales,

* diseñe servicios generales especiales para distintos tipos de lectores.

* participe en redes de colaboración que beneficien a su comunidad y a otras,

* seleccione sitios para sus usuarios, e

* identifique sitios WEB bajo criterios de calidad y transparencia.

Por lo tanto, las funciones sustantivas de la biblioteca pública -atender digitalmente la confiabilidad y accesibilidad de los contenidos que ofrece y buscar la versatilidad que requiera el lector, así como reducir la complejidad de los servicios y adecuarlos a los distintos grupos de lectores- , se fortalecerán en la medida en que la biblioteca logre ofrecer a sus usuarios nuevos medios de manejo fácil y rápido que le permitan acceder al mundo de la información, y que participe de este modo en los procesos de capacitación de su comunidad proporcionándole guías para identificar una información confiable y aportándole soluciones a las necesidades informativas desde las más simples hasta las más complejas.

En la sociedad de la información, la biblioteca pública está llamada a jugar un papel estratégico si logra mantenerse como un sistema público, gratuito y equilibrador entre el mundo tipográfico y el ciberespacio; entre la subcultura

19 Emir José Suaiden y Ramiro Arango. "La biblioteca pública y la sociedad de la información: globalización y escenarios”, en: El libro en Améica Latina y d Caribe, núm. 87 (ene./ jun.) 1999, Colombia, pp. 28-38. 
mediática y la cultura que genera conocimiento; entre los privilegiados y los marginados; entre la "generacóncom" y las "generadoneslibro".

La biblioteca pública deberá cuidar con todo esmero el desarrollo de sus colecciones, con el fin de constituirse en una alternativa distinta a la de la literatura banal producida y distribuida para el fácil acceso mental y económico, e incluso apoyar a los lectores mediante guías de orientación de lectura (ræadingadvisary), sitios creados por grupos de la sociedad civil. Algunas de estas guías, relacionadas con literatura de diversos géneros para niños, jóvenes y adultos, son creadas por casas editoras de prestigio, pero otras no, por ello la biblioteca puede ayudar a seleccionar estos sitios para hacer transparente su procedencia.

D os son los aspectos que deberá cubrir la biblioteca para que sea realmente significativa: ayudas para seleccionar fuentes y sitios de lectura, e instrucciones para el manejo de éstos. ${ }^{20}$

\section{BIBLIOGRAFÍA}

AGUADERO Fernández, Francisco. La socedaddelainfomacón: viuirend sigoxx, Madrid: Acento Editorial, 1997.

Bo URD IEU, Pierre. Sdarelatdeision tr. de Thomas Kauf, 2a ed. Barcelona: Anagrama, 1998, $138 \mathrm{p}$.

D AVIS Smith, Elaime. "A comparison of the effects of new technology on searching habits in industrial and academic institutions", pp. 57-66, en Joumal of InfomationSaiene, no. 19, Elsevier Science Publishers B. V., 1993.

FO SMIRE, Michael; Elizabeth Y oung. "Free scholary electronic journals: what access do college and university libraries provide?", pp. 500-508. En: CdlegeandRearchLibranies vol. 61, núm. 6, nov. 2000.

FREIRE, Paulo. La impotania de leer y d proeso de liberacoón tr. Stella Mastrangelo, México: Siglo Xxi Editores, 1985, 176 p.

JiTRIK, Noé. Lectura y altura, México: UNAM, Dirección General de Publicaciones y Fomento Editorial, 1998, 85 p.

20 Mayores datos sobre las guías se encuentran en los artículos:

Pollit, A. Steven. "The key role of classification and indexing in view-based searching". En: http:/ / www.hud.ac.uk/ schools/ cedar/ polifla.html. Fecha de consulta: 19 de junio de 2001. SCHULTS, Kristine. "An overview of readers' advisory service with evaluations of related websites". En: Aqquisitions Libranian no. 23, pp. 21-33, 2000. 
NUA Internet Surveys. Disponible en:

http:/ / www.nua.ie/ surveys/ analysis/graphs charts/ index.html

RIFKIN, Jeramy. Laeadd accesa lareuduaóndelanueąeonoma Barcelona: Paidós, 2000, 366 p.

SARTORI, Giovanni. Hombvidans Lasoiedadtdedingida, México: Taurus, 2000.

SCHIFFRIN, André. La edidónsineditores tr. Eduard G onzalo, Barcelona: Destino, 2000, $151 \mathrm{p}$.

SHERA, Jesse H. Los fundanentos de la eduracón biblictedógica; tr. Surya Peniche de Sánchez Macgrégor (Monografías, 9), México:UNAM-CUIB, 1990, $520 \mathrm{p}$.

SUAID EN, EmirJosé y Ramiro Arango: "La biblioteca públicay la sociedad de la información: globalización y escenarios", en: El libroenAméica Latimayd Caribe, no. 87 (ene./ jun.) 1999, Colombia, pp 28-38.

WEBSTER, Frank. Theeries of theinfomationsoidy. Londres y Nueva Y ork: Routledge, 1999, $257 \mathrm{p}$. 